\title{
Microhardness Anisotropy and the Indentation Load/Size Effect in $\mathrm{MgO} \cdot x \mathrm{Al}_{2} \mathrm{O}_{3}$ Single Crystals
}

\author{
Hong LI, Hisayuki SUEMATSU*, Takayoshi ISEKI* and Richard C. BRADT \\ Mackay School of Mines, University of Nevada-Reno, Reno, Nevada 89557-0047, USA \\ *Department of Inorganic Materials, Tokyo Institute of Technology, O-okayama, Meguro-ku, Tokyo

\section{$\mathrm{MgO} \cdot x \mathrm{Al}_{2} \mathrm{O}_{3}$ 単結晶の硬度の異方性及び荷重依存性}

\author{
Hong LI · 末松久幸* · 井関孝善* - Richard C. BRADT
}

Mackay School of Mines, University of Nevada-Reno, Reno, Nevada 89557-0047 USA

*東京工業大学工学部, 152 東京都目黒区大岡山2-12-1

[Received May 7, 1991; Accepted July 18, 1991]

\begin{abstract}
The Knoop microhardness profiles were determined on the (100) of $\mathrm{MgO} \cdot 1 \mathrm{Al}_{2} \mathrm{O}_{3}$ and $\mathrm{MgO} \cdot 3 \mathrm{Al}_{2} \mathrm{O}_{3}$ single crystals. The $\langle 100\rangle$ were the hardness maxima and the $\langle 110\rangle$ the hardness minima for both compositions. The nonstoichiometric spinel was the most anisotropic, but the stoichiometric $\mathrm{MgO} \cdot 1 \mathrm{Al}_{2} \mathrm{O}_{3}$ crystal had the larger load-independent "true" hardness for all indentation orientations on the $(100)$. The hardness profiles were found to be dominated by the $\{111\}\langle 1 \overline{10}\rangle$ primary slip systems from comparison with the calculated ERSS diagrams for the crystals, although differences in the profile shapes were evident. The nonstoichiometric spinel exhibited the greater indentation load/size effect in terms of the Meyer's Law exponent.
\end{abstract}

Key-words : Spinel, Meyer's Law, Hardness anisotropy, Microindentation, Stoichiometry

\section{Introduction}

Deformation processes relating to dislocation motion and the active slip systems of $\mathrm{MgO} \cdot x \mathrm{Al}_{2} \mathrm{O}_{3}$ spinel single crystals*1 have been extensively studied for several decades. Following Hornstra's prediction $^{1)}$ of the $\{111\}\langle 1 \overline{1} 0\rangle$ primary slip system in stoichiometric spinel $\left(\mathrm{MgO} \cdot 1 \mathrm{Al}_{2} \mathrm{O}_{3}\right)$, Choi et al. ${ }^{2)}$ studied the high temperature deformation $\left(1600^{\circ} \mathrm{C}\right)$ of polycrystalline stoichiometric $\mathrm{Mg}-\mathrm{Al}$ spinel and confirmed that the $\{111\}\langle 1 \overline{1} 0\rangle$ slip system was active. Single crystal spinel was subsequently studied by Lewis ${ }^{3)}$ at high temperatures $\left(1300^{\circ} \mathrm{C}\right.$ to $\left.1520^{\circ} \mathrm{C}\right)$ in one of the first reports on the effect of stoichiometry on the deformation. Lewis reported that the slip system in nonstoichiometric spinel $\left(\mathrm{MgO} \cdot x \mathrm{Al}_{2} \mathrm{O}_{3}\right.$, $x=1.5,2.5$ and 3.5$)$ is the $\{110\}\langle 1 \overline{1} 0\rangle$. For the $x=3.5$ spinel, he also observed the $\{111\}\langle 1 \overline{1} 0\rangle$, but considered that it was because of the high ratio of resolved shear stress $\left(\tau_{111} / \tau_{110}=1.5\right)$, which resulted from the oriented test specimens.

Newey and Radford ${ }^{4)}$ also studied the high temper-

*1 In some of the literature, the nonstoichiometric spinels are specified as $\left(\mathrm{Al}_{2} \mathrm{O}_{3}\right)_{n} \mathrm{MgO}$. ature deformation of the $\mathrm{Mg}-\mathrm{Al}$ spinels $(x=1,2$ and $3)$. They reported the $\{111\}\langle 1 \overline{1} 0\rangle$ slip system for both the $\mathrm{MgO} \cdot 1 \mathrm{Al}_{2} \mathrm{O}_{3}$ and the $\mathrm{MgO} \cdot 3 \mathrm{Al}_{2} \mathrm{O}_{3}$ spinels, but that the $\{110\}\langle 1 \overline{1} 0\rangle$ was dominant for the $\mathrm{MgO} \cdot 2 \mathrm{Al}_{2} \mathrm{O}_{3}$. Doukhan et al. ${ }^{5), 6)}$ addressed the creep behavior of $\mathrm{MgO} \cdot x \mathrm{Al}_{2} \mathrm{O}_{3}(x=1.1$ and 1.8) spinel single crystals at $1520^{\circ} \mathrm{C}$. They confirmed the $\{111\}$ $\langle 1 \overline{1} 0\rangle$ slip system for the $x=1.1 \mathrm{Mg}-\mathrm{Al}$ spinel, but also observed the $\{110\}\langle 1 \overline{10}\rangle$ for the $x=1.8 \mathrm{Mg}-\mathrm{Al}$ spinel. Donlon et al. ${ }^{9)}$ reported dislocation dissociation on the $\{111\}\langle 1 \overline{10}\rangle$ slip system for the nonstoichiometric $\left(\mathrm{MgO} \cdot 3.5 \mathrm{Al}_{2} \mathrm{O}_{3}\right)$ spinel at $1500^{\circ} \mathrm{C}$, which confirms the previous report by Newey and Radford. Heuer, Mitchell and coworkers ${ }^{7)-9)}$ have also studied the high temperature deformation of spinel between $1790^{\circ}$ and $1895^{\circ} \mathrm{C}$. The $\{111\}\langle 1 \overline{10}\rangle$ slip system was confirmed for the stoichiometric $\mathrm{Mg}-\mathrm{Al}$ spinel single crystals and the $\{110\}\langle 1 \overline{10}\rangle$ for the nonstoichiometric $\mathrm{Mg}-\mathrm{Al}$ spinel single crystals. Recently, Suematsu et al.10),11) studied nonstoichiometric $\left(\mathrm{MgO} \cdot 2.9 \mathrm{Al}_{2} \mathrm{O}_{3}\right)$ single crystal spinel at temperatures between $1100^{\circ}$ and $1500^{\circ} \mathrm{C}$, where dislocation processes were observed to be those of the $\{110\}\langle 1 \overline{1} 0\rangle$ slip system. The effect of the spinel stoichiometry on the stacking fault energy has been addressed in considerable detail by Welsch et al., ${ }^{12)}$ who suggest that the stacking fault energy of $\mathrm{MgO} \cdot x \mathrm{Al}_{2} \mathrm{O}_{3}$ decreases as the composition ratio, $x$, increases. Duclos et al. ${ }^{13)}$ have studied the effect of stoichiometry on the creep of $\mathrm{MgO} \cdot x \mathrm{Al}_{2} \mathrm{O}_{3} \quad(x=1.1$, 1.8 and 3) spinels and concluded that the ease of glide on the $\{110\}\langle 1 \overline{1} 0\rangle$ slip plane of the nonstoichiometric spinel is the result of the high intrinsic mobility of the dislocations.

Studies addressing the hardness of $\mathrm{MgO} \cdot x \mathrm{Al}_{2} \mathrm{O}_{3}$ single crystal spinels do not appear to be as numerous as those for the slip systems. Mineralogy texts usually report a Moh's hardness of about 8.14) In their summary, Young and Millman ${ }^{15)}$ have reported that the Vickers microhardness varies from 1378 to $1505 \mathrm{~kg} / \mathrm{mm}^{2}$ on the (111) plane of spinel single crystals, while Akimune and Bradt ${ }^{16)}$ reported a 
Knoop microhardness of $1508 \mathrm{~kg} / \mathrm{mm}^{2}$ on the (111). Viechnicki et al. ${ }^{17)}$ have studied precipitation effects on the Knoop microhardness of nearly stoichiometric $\mathrm{Mg}-\mathrm{Al}$ spinel single crystals. They reported 100 $\mathrm{g}$ test load Knoop microhardness values of $1820 \mathrm{~kg} /$ $\mathrm{mm}^{2}$ in the $\langle 100\rangle$ directions, but only $1690 \mathrm{~kg} / \mathrm{mm}^{2}$ in the $\langle 110\rangle$ on the $(100)$. The difference between these hardnesses is about $8 \%$. Bansal and Heuer ${ }^{18)}$ measured the Knoop microhardnesses in the $\langle 100\rangle$ and the $\langle 110\rangle$ on the (100) plane during precipitation in $\mathrm{MgO} \cdot 3.5 \mathrm{Al}_{2} \mathrm{O}_{3}$ spinel single crystals. They observed that the $\langle 100\rangle$ is consistently harder than the $\langle 110\rangle$ by about $10 \%$, although the actual microhardnesses fluctuated during the precipitation process. Only Akimune and Bradt ${ }^{16)}$ have specifically addressed the Knoop microhardness anisotropy of stoichiometric $\left(\mathrm{MgO} \cdot 1 \mathrm{Al}_{2} \mathrm{O}_{3}\right)$ spinel single crystals, measuring both the (100) and the (111) planes. Their results indicate that the microhardness is highly anisotropic on the (100), but essentially isotropic on the (111) plane. The trend that the $\langle 100\rangle$ is harder than the $\langle 110\rangle$ on the (100) plane, about 1800 to $1500 \mathrm{~kg} / \mathrm{mm}^{2}$, is consistent with the other spinel microhardnesses that have been reported by Viechnicki et al. ${ }^{17)}$ and Bansal and Heuer. ${ }^{18)}$ Zinkle ${ }^{19)}$ recently studied the effect of ion-implantation on the hardness of polycrystalline $\mathrm{MgO} \cdot 1 \mathrm{Al}_{2} \mathrm{O}_{3}$ spinel and observed that the hardness of the irradiated spinels increases about $5 \%$. This increase in hardness by ion-implantation is addressed in terms of the creation of interstitial dislocation loops, which were observed to be of the $\{111\}\langle 1 \overline{1} 0\rangle$ and the $\{110\}$ $\langle 1 \overline{1} 0\rangle$ types.

In spite of these numerous studies of $\mathrm{Mg}-\mathrm{Al}$ spinels, there has not been a systematic investigations of the influence of the stoichiometry of $\mathrm{Mg}-\mathrm{Al}$ spinels on either their hardness or their hardness anisotropy. Neither has there been a study of the indentation load/size effect, the ISE, on the microhardness or the microhardness anisotropy of spinel. This paper reports a study of these phenomena. The stoichiometry effect on the microhardness and the related anisotropy profiles of $\mathrm{Mg}-\mathrm{Al}$ spinel single crystals were determined on the (100) planes of high purity synthetic stoichiometric $\left(\mathrm{MgO} \cdot 1 \mathrm{Al}_{2} \mathrm{O}_{3}\right)$ and nonstoichiometric $\left(\mathrm{MgO} \cdot 3 \mathrm{Al}_{2} \mathrm{O}_{3}\right)$ single crystals. The indentation load/size effect on the microhardness of these crystals is considered in terms of both the classical Meyer's Law ${ }^{20)}$ and a normalized form of Meyer's Law which has been proposed by $\mathrm{Li}$ and Bradt. ${ }^{21)}$

\section{Experimental procedure}

According to the earlier study of Akimune and Bradt, 16) the Knoop microhardness anisotropy of $\mathrm{Mg}-\mathrm{Al}$ spinel is significant on the (100); however, on the (111) plane the microhardness is essentially isotropic. Therefore, in this study, only the Knoop microhardnesses on the (100) of the crystals have been addressed. Single crystals of $\mathrm{MgO} \cdot 1 \mathrm{Al}_{2} \mathrm{O}_{3} * 2$ and $\mathrm{MgO} \cdot 3 \mathrm{Al}_{2} \mathrm{O}_{3} * 3$ were obtained from commercial sources. Previous to the specimen mounting, both surfaces and the $\langle 100\rangle$ crystallographic orientations of specimens were confirmed by X-ray diffraction. Then each specimen was mounted using the cold mounting method with a mixture of epoxy powder and hardener. Subsequent polishing was carried out by using $15,5,3,1$ and finally $0.25 \mu \mathrm{m}$ diamond pastes to achieve scratch free, mirror-like surfaces for the Knoop indentation microhardness measurements.

Using a Shimadzu microindenter, Knoop microhardness measurements were made at room temperature for indenation test loads of 50,100,200 and 300 $\mathrm{g}$ at an indentation rate of $0.017 \mathrm{~mm} / \mathrm{s}$ for a dwell time of $15 \mathrm{~s}$. The crystallographic orientations which were measured on the (100) planes were from the $[001]$ through the $[011]$ to the $[010]$, where the $[\mathrm{hkl}]$ is parallel to the long axis of the Knoop indenter. Cracks occasionally initiated from the indentation corners for test loads above $300 \mathrm{~g}$, thus not allowing for accurate hardness measurements above that level of test load. In the microindentation hardness test, the long diagonal of the Knoop impression was measured immediately after the indentation. The Knoop hardness number $(K H N)$ at each load level was calculated from the long diagonal of the indentation by applying:

$$
K H N=\frac{14229 P}{d^{2}} \quad\left(\mathrm{~kg} / \mathrm{mm}^{2}\right)
$$

where $P$ is the indentation test load (in grams) and $d$ is the long diagonal of the Knoop indentation (in micrometers). The Knoop microhardness values are reported as the averages for 25 individual indentations at each orientation and test load. The 95\% confidence intervals are reported as determined by applying the " $t$ " distribution for the hardnesses and all subsequent parameters derived from the analysis and the graphical presentations.

\section{Results and discussion}

\subsection{Knoop microhardness anisotropy}

The (100) plane Knoop microhardness profiles for the $\mathrm{MgO} \cdot 1 \mathrm{Al}_{2} \mathrm{O}_{3}$ and $\mathrm{MgO} \cdot 3 \mathrm{Al}_{2} \mathrm{O}_{3}$ single crystals are depicted in Figs. 1 (a) and (b), respectively. The error-bars on the $50 \mathrm{~g}$ results are the largest $95 \%$ confidence intervals for the data. The apparent microhardnesses of these two spinel single crystals are similar, ranging from about 1200 to $2000 \mathrm{~kg} /$ $\mathrm{mm}^{2}$, dependent on the test load. In terms of the familiar Moh's scale, this is between about 7.6 and 8.3 , which compares favorably to the value of 8 that has been reported. ${ }^{14)}$ For both of these $\mathrm{Mg}-\mathrm{Al}$ spinels, the microhardness profiles on the (100) plane exhibit hardness maxima in the $\langle 100\rangle$ and a

\footnotetext{
*2 Union Carbide Corp.; San Diego, CA, USA

*3 Shinko Co.; Tokyo, Japan
} 

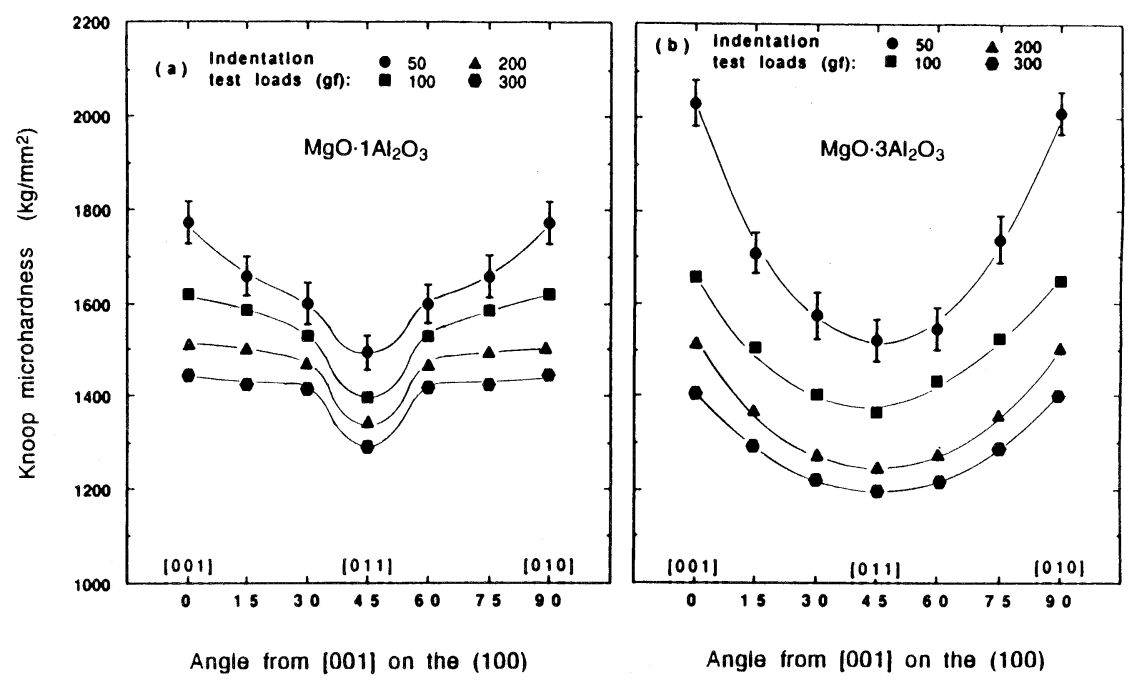

Fig. 1. The Knoop microhardness profiles of the single crystals on their (100) planes: (a) $\mathrm{MgO} \cdot 1 \mathrm{Al}_{2} \mathrm{O}_{3}$ and (b) $\mathrm{MgO}_{3} \cdot 3 \mathrm{Al}_{2} \mathrm{O}_{3}$.

minima in the $\langle 110\rangle$. This general microhardness profile is in agreement with the previous results of Akimune and Bradt on the (100) of stoichiometric $\mathrm{MgO} \cdot 1 \mathrm{Al}_{2} \mathrm{O}_{3} \cdot{ }^{16)}$ It is also similar to the result of Ito on the (100) of $\mathrm{MnFe}_{2} \mathrm{O}_{4}$, which also has the spinel structure $^{22)}$ and that of Dekker and Rieck ${ }^{23)}$ for the (100) plane of a $\mathrm{Mn}_{1.83} \mathrm{Al}_{1.17} \mathrm{O}_{4}$ spinel single crystal.

Table 1 summarizes parameters descriptive of the Knoop microhardness anisotropy of these spinel single crystals. The hardness anisotropy can be defined in terms of either the simple ratio of $H_{\max } / H_{\min }$ or in terms of the hardness difference as $\left(H_{\max }-H_{\min }\right) /$ $\left(H_{\max } \cdot H_{\min }\right)^{1 / 2}$. Although these definitions as applied to the Knoop microhardness anisotropy are slightly different, it is evident that both yield similar trends and the same conclusions, namely that the extent of the Knoop microhardness anisotropy of the stoichiometric $\left(\mathrm{MgO} \cdot 1 \mathrm{Al}_{2} \mathrm{O}_{3}\right)$ spinel is less than that of the nonstoichiometric $\left(\mathrm{MgO} \cdot 3 \mathrm{Al}_{2} \mathrm{O}_{3}\right)$ spinel and also that the extent or degree of microhardness anisotropy appears to decrease as the indentation test load increases for both crystals. These features are presented in Fig. 2 where the Knoop microhardness anisotropy is observed to decrease with increasing indentation test load. Comparing these two Knoop microhardness anisotropy profiles with the one reported by Akimune and Bradt, ${ }^{16)}$ they are in good agreement. The Knoop microhardness anisotropy reported in their study was about $20 \%$ between the $\langle 100\rangle$ and the $\langle 110\rangle$ orientations, which is about the same as illustrated in Fig. 2 for these two spinel crystals.

The representation of the microhardness anisotropy in Fig. 2 suggests a possible relationship between the degree or extent of this anisotropy and the microhardness indentation test load. The form of the anisotropy versus the test load closely resembles the typical hardness versus indentation test load (or indentation size) trend. This suggests that there may exist some fundamental relationship between
Table 1. Knoop microhardness anisotropy of the $\mathrm{MgO} \cdot x \mathrm{Al}_{2} \mathrm{O}_{3}$ single crystals on the (100).

\begin{tabular}{lcccc}
\hline $\begin{array}{l}\text { Microindentation } \\
\text { Test Load }(\mathrm{g})\end{array}$ & $\left(\frac{\mathrm{H}_{\max }}{\mathrm{H}_{\min }}\right) \times 100 \%$ & $\left(\frac{\mathrm{H}_{\max }-\mathrm{H}_{\min }}{\left(\mathrm{H}_{\max } \mathrm{H}_{\min }\right)^{1 / 2}}\right) \times 100 \%$ \\
\hline \multirow{2}{*}{50} & 118.8 & 133.8 & 17.2 & 29.2 \\
100 & 116.0 & 121.3 & 14.9 & 19.3 \\
200 & 113.0 & 121.7 & 12.2 & 19.7 \\
300 & 112.0 & 117.4 & 11.3 & 16.1 \\
\hline
\end{tabular}

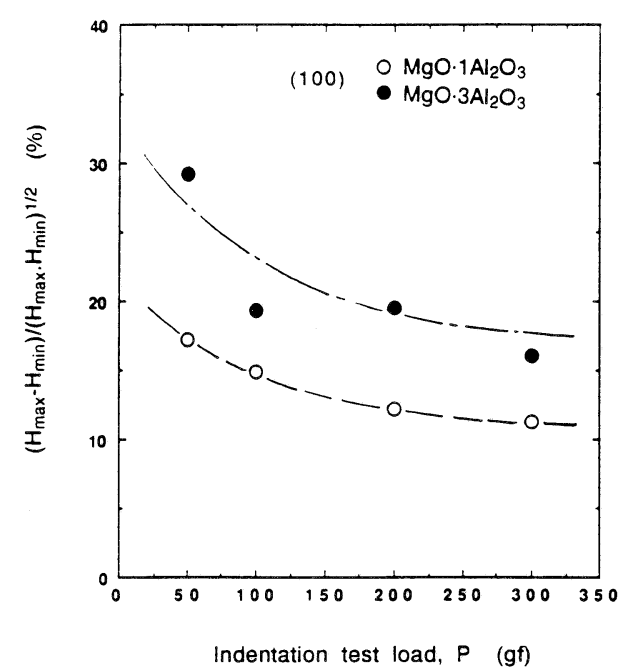

Fig. 2. Effect of the indentation test load on the microhardness anisotropy of spinel single crystals on the (100).

the microindentation hardness profiles and the indentation test load/size effect, the ISE. However, the details of that relationship are beyond the scope of this paper and will be addressed in a subsequent study.

It is apparent that there exist differences as well as similarities in the microhardness anisotropy profiles and the Knoop microhardnesses between these two 
different stoichiometry spinel single crystals. Any similarity must be certainly related to the crystal structure, as the same chemical species and chemical bonding are present in both crystals. However, the microhardness profiles of these two $\mathrm{Mg}-\mathrm{Al}$ spinels are distinctly different. The stoichiometric spinel profile exhibits a central depression and well-defined plateau-like regions towards the $\langle 100\rangle$ directions. This effect is accented with increasing microindentation test load, whereas no plateau-like regions exist for the nonstoichiometric crystal, which exibits a smooth parabolic profile. This difference can be further considered through the concept of the effective resolved shear stress (ERSS), as has been advanced by Brookes and coworkers. ${ }^{24)}$

The primary slip system for the stoichiometric $\left(\mathrm{MgO} \cdot 1 \mathrm{Al}_{2} \mathrm{O}_{3}\right)$ spinel has been confirmed to be the $\{111\}\langle 1 \overline{1} 0\rangle$ by many studies as previously reviewed. For nonstoichiometric $\left(\mathrm{MgO} \cdot x \mathrm{Al}_{2} \mathrm{O}_{3}, x>1\right)$ spinel, the operative slip system has been reported to be the $\{110\}\langle 1 \overline{1} 0\rangle$. However, there exists some controversy as to whether the $\{111\}\langle 1 \overline{1} 0\rangle$ slip system is also operative for the nonstoichiometric $\mathrm{Mg}-\mathrm{Al}$ spinels and to what extent it participates in the deformation.

Ito $^{22)}$ has measured the Knoop microhardness profile of $\mathrm{Mn}-\mathrm{Zn}$ ferrite spinel single crystals on the $(100)$, as well as on the (110) and the (210) planes. On the (100) plane of the $\mathrm{MnFe}_{2} \mathrm{O}_{4}$, Ito's Knoop microhardness profile is very similar to that reported for the nonstoichiometric spinel in this study. He concluded that both the $\{111\}\langle 1 \overline{1} 0\rangle$ and the $\{110\}\langle 1 \overline{1} 0\rangle$ slip systems were responsible for the microhardness profile of $\mathrm{MnFe}_{2} \mathrm{O}_{4}$. Dekker and Rieck ${ }^{23)}$ have studied the Vickers microhardnesses of various spinel single crystals. On the $\{100\}$ of a $\mathrm{Mn}_{1.83} \mathrm{Al}_{1.17} \mathrm{O}_{4}$ single crystal, they observed that the $\langle 100\rangle$ directions are harder than the $\langle 110\rangle$ directions, which com- pares favourably with the hardness anisotropies for the $\mathrm{Mg}-\mathrm{Al}$ spinels in this study and $\mathrm{Mn}-\mathrm{Zn}$ ferrite spinels measured by Ito. ${ }^{22)}$ However, they used the Vickers indenter which creates a much deeper impression than the Knoop indenter at comparable indentation test loads. This requires that more material flow out of the impression and probably promotes extensive slip on secondary and perhaps even tertiary slip systems, nevertheless the orientation of the profile is similar.

For the basis of discussion, it is logical to attempt to apply the ERSS concept as advanced by Brookes and coworkers under the assumptions that the $\{111\}$ $\langle 1 \overline{1} 0\rangle$ is the dominant slip system for the stoichiometric $\mathrm{MgO} \cdot 1 \mathrm{Al}_{2} \mathrm{O}_{3}$ spinel, while the $\{111\}\langle 1 \overline{1} 0\rangle$ and the $\{110\}\langle 1 \overline{1} 0\rangle$ may both contribute significantly to the anisotropy of the nonstoichiometric spinel. The ERSS diagrams can be readily constructed for the Knoop indentations on the (100) planes. Detailed information on ERSS calculations has been introduced by Brookes et al.,24) and is not included here. The interested reader should refer to his original paper. For the ERSS calculations, each individual ERSS line is first calculated, then the resultant ERSS diagram is constructed by a summation of the most dominant ERSS curves (dotted lines), those which have the highest magnitude ERSS within the region from the [001] to the [010] on the (100) plane. The microhardness profile is then expected to be the inverse of the ERSS diagram, if those slip systems dominate the microhardness.

Figure 3(a) presents the resulting ERSS diagram for the $\{111\}\langle 110\rangle$ primary slip system, while Fig. 3 (b) illustrates the ERSS diagram for the $\{110\}$ $\langle 1 \overline{1} 0\rangle$ primary slip system. These two ERSS diagrams are essentially the opposite, that is $45^{\circ}$ out of phase. As the ERSS diagram is inversely related to the microhardness anisotropy profile, a comparison
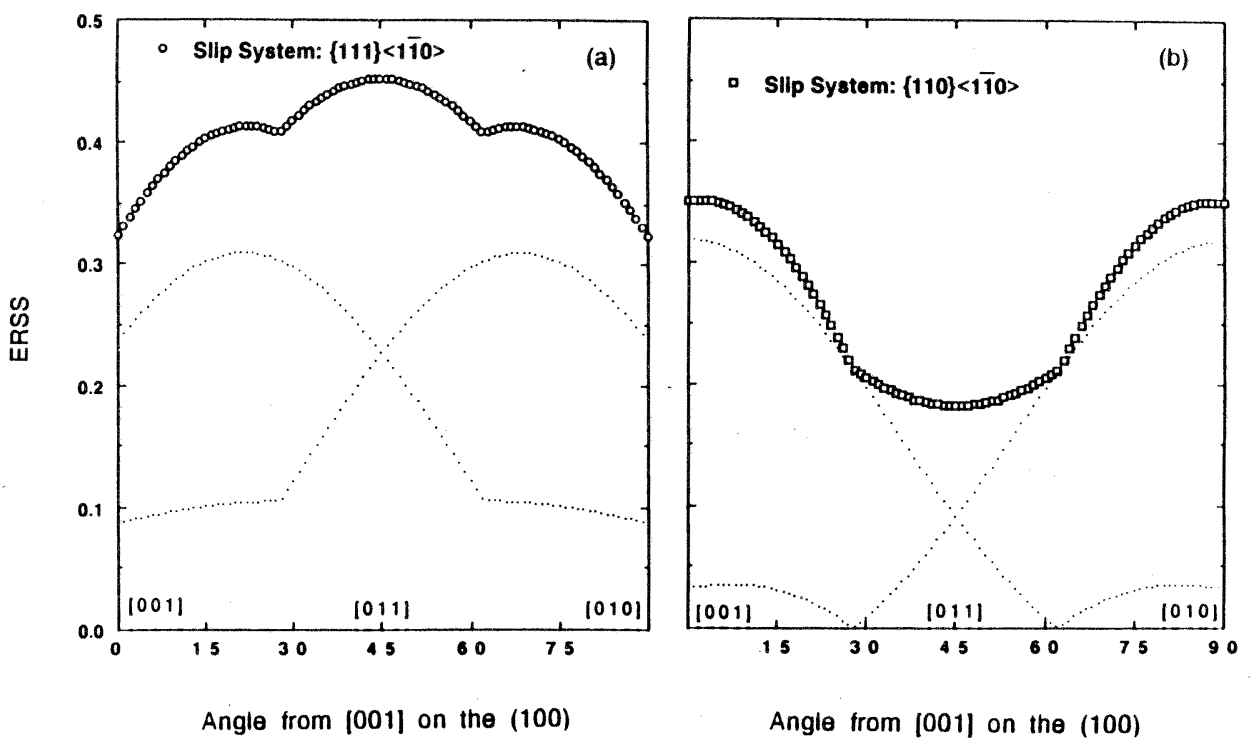

Fig. 3. The calculated ERSS diagrams for (a) the $\{111\}\langle 1 \overline{1} 0\rangle$ and (b) the $\{110\}\langle 1 \overline{1} 0\rangle$ slip systems. 
of Fig. 3 with Fig. 1 clearly establishes that it is the $\{111\}\langle 1 \overline{1} 0\rangle$ primary slip system which dominates the deformation processes which determine the microhardness profiles for both of these $\mathrm{MgO}$. $x \mathrm{Al}_{2} \mathrm{O}_{3} \quad(x=1,3)$ spinel single crystals. However, further discussion is appropriate.

Figures 3 (a) and 1(a) can be directly compared. In the calculated ERSS diagram of Fig. $3(\mathrm{a})$ for the $\{111\}\langle 1 \overline{1} 0\rangle$, it is apparent that there are three distinct regions. A central high ERSS region extends over about $30^{\circ}$ and is flanked by two lower ERSS symmetrical regions extending about $30^{\circ}$ from the $\langle 100\rangle$ toward the [011]. This is practically the exact inverse of the Knoop microhardness anisotropy profile in Fig. 1 (a), which also exhibits three distinct regions. Thus it must be concluded that the microhardness profile of the stoichiometric $\mathrm{MgO} \cdot 1 \mathrm{Al}_{2} \mathrm{O}_{3}$ spinel on the (100) is determined primarily by the $\{111\}\langle 1 \overline{1} 0\rangle$ slip system. This is in agreement with Hornstra's original prediction ${ }^{1)}$ and the experimental observations of Choi et al., ${ }^{2)}$ Newey and Radford,4) Doukhan et al.5),6) and Mitchell et al.8) The form of the microhardness profile for the stoichiometric $\mathrm{MgO} \cdot 1 \mathrm{Al}_{2} \mathrm{O}_{3}$ spinel follows the behavior predicted by the ERSS diagram for the $\{111\}$ $\langle 1 \overline{10}\rangle$ primary slip systems.

However, the microhardness profile of the nonstoichiometric $\mathrm{MgO} \cdot 3 \mathrm{Al}_{2} \mathrm{O}_{3}$ spinel presents some contradictions, or at least is not as clear in origin as that for the stoichiometric single crystal. Whereas several reseachers ${ }^{4)-6), 9), 13)}$ have reported the $\{110\}$ $\langle 1 \overline{10}\rangle$ to be the primary slip system in nonstoichiometric spinel, particularly for deformation at elevated temperatures, the calculated ERSS diagram for that slip system yields the incorrect maxima and minima for the experimentally observed microhardness profile. From the resuits of this study, it must be concluded that the $\{110\}\langle 1 \overline{1} 0\rangle$ does not dominate the microhardness profile of $\mathrm{MgO} \cdot 3 \mathrm{Al}_{2} \mathrm{O}_{3}$ on the (100). Rather, the microhardness profile for the nonstoichiometric crystal is in agreement with that predicted for the $\{111\}\langle 1 \overline{1} 0\rangle$ slip system dominance the same as for the stoichiometric crystal. The origin of the dominance of the $\{111\}\langle 1 \overline{1} 0\rangle$ slip system is not clear, it may be related to the highly compressive stress state beneath the indenter or to the fact that the deformation was introduced at room temperature.

Although the overall microhardness profile for the $\mathrm{MgO} \cdot 3 \mathrm{Al}_{2} \mathrm{O}_{3}$ crystal on the $(100)$ generally ascribes to the form predicted for the $\{111\}\langle 1 \overline{1} 0\rangle$ primary slip system, if Figs. 1(a) and 1(b) are compared, there is no doubt that the nonstoichiometric crystal has a different shape to its microhardness profile. The plateau-like regions of the stoichiometric $\mathrm{MgO} \cdot 1 \mathrm{Al}_{2} \mathrm{O}_{3}$ spinel are not present and there is no evidence for three separate regions of microhardness behavior on the (100) of the $\mathrm{MgO} \cdot 3 \mathrm{Al}_{2} \mathrm{O}_{3}$ single crystal. Rather the profile appears to be quite smooth and parabolic in form.

If the specific microhardnesses are considered for these two spinel single crystals, then it becomes evident that the nonstoichiometric crystal becomes harder for those orientations which are near to the $\langle 100\rangle$. This is precisely the orientation where the ERSS diagram for the $\{110\}\langle 1 \overline{1} 0\rangle$ predicts the highest resolved shear stress or the greatest propensity for slip on the $\{110\}\langle 1 \overline{1} 0\rangle$. This suggests that it should be the lowest hardness when the $\{110\}\langle 1 \overline{10}\rangle$ slip system is dominant. However, that slip system is not dominant during the indentation measurements, yet it might be active. One possible situation that allows for the $\{110\}\langle 1 \overline{1} 0\rangle$ slip and increased hardness is that for those orientations near to the $\langle 100\rangle$ in the $\mathrm{MgO} \cdot 3 \mathrm{Al}_{2} \mathrm{O}_{3}$ crystal, both the $\{111\}$ and $\{110\}$ slip systems are active. Researchers have observed the presence of multiple slip near to indentations ${ }^{22)}$ and Ito has done so for the spinel structure. If the two slip systems were simultaneously active, perhaps there would occur much greater work hardening near to the $\langle 100\rangle$ orientations, thus leading to the higher harderness which are observed in the $\mathrm{MgO} \cdot 3 \mathrm{Al}_{2} \mathrm{O}_{3}$ and are evident in Fig. 1 (b).

\subsection{The indentation load/size effect, Meyer's Law}

Addressing the Knoop microhardness values as presented in Figs. 1(a) and 1(b) at each level of individual indentation test load, there is not any absolute way in which to distinguish as to which of the two crystals is consistently the harder. For example, except for the $\langle 100\rangle$ directions, the stoichiometric $\left(\mathrm{MgO} \cdot 1 \mathrm{Al}_{2} \mathrm{O}_{3}\right)$ spinel generally appears to be harder than the nonstoichiometric $\left(\mathrm{MgO} \cdot 3 \mathrm{Al}_{2} \mathrm{O}_{3}\right)$ spinel. To clearly distinguish the microhardness difference between the crystals, it is constructive to analyze the load dependence of the hardness behavior of the two crystals. Many microhardness studies ${ }^{25)-29)}$ have shown that Meyer's Law:

$$
P=A d^{n}
$$

can be generally applied to describe the indentation load/size effect for a variety of materials and single crystals, both metals and ceramics, as well as for different indenter geometries (Knoop, Vickers and Brinell). In Eq. (2), $P$ and $d$ have their original meanings as in Eq. (1), while $A$ and $n$ are descriptive parameters. The conventional Meyer's Law of Eq. (2) can be expressed in the logarithmic form as: $\log P=\log A+n \log d$

Applying Eq. (3) to the hardness results depicted in Figs. 1(a) and 1(b), the indentation load/size effect can be directly addressed for these crystals.

Figure 4 illustrates the Meyer's Law relationship on the (100) plane for the two $\mathrm{Mg}-\mathrm{Al}$ spinels. Four orientations from the $[001]$ to the $[011]$ at $15^{\circ}$ intervals are presented. It is evident that the Meyer's Law relationship is followed by the experimental data as the linear regression coefficients $\left(r^{2}\right)$ of the plots are exceed 0.99. It is also apparent that the 


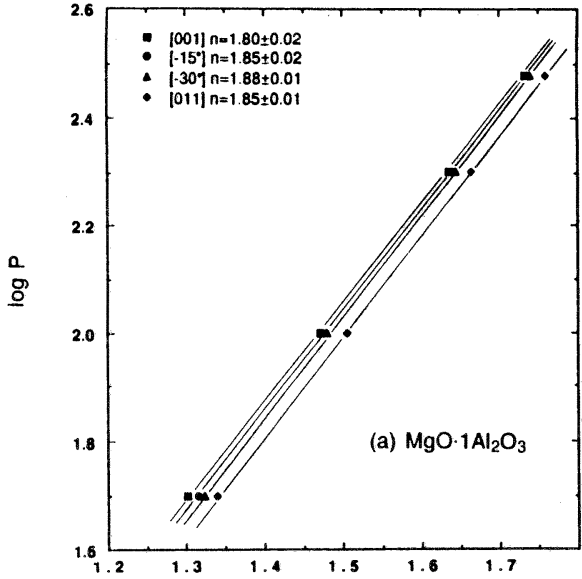

$\log d$

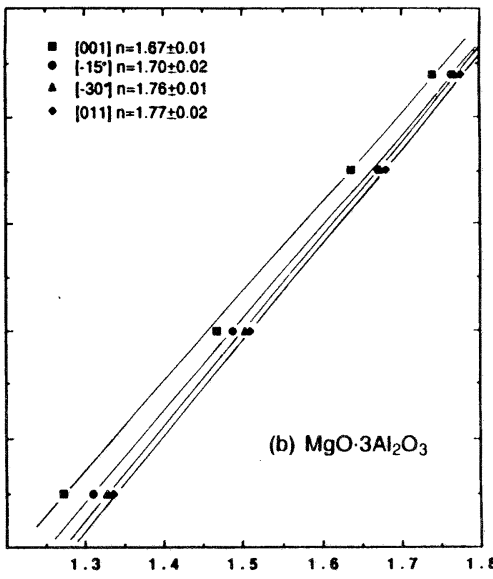

$\log d$

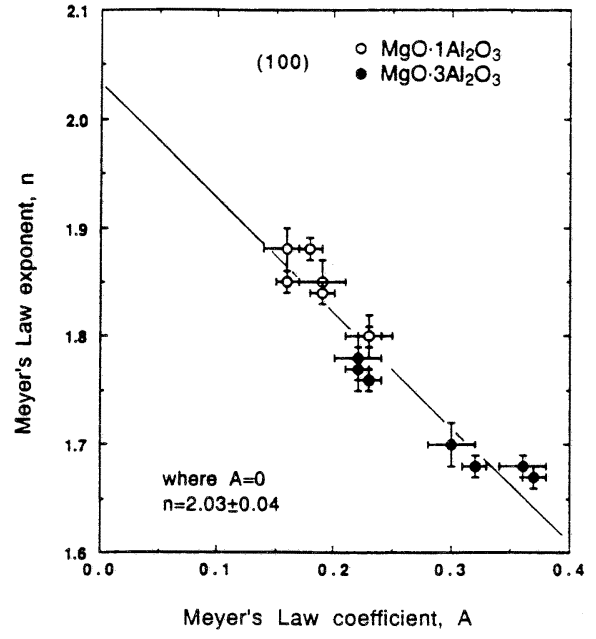

Fig. 5

Fig. 4

Fig. 4. The classical Meyer's Law relationship on the (100) of the $\mathrm{MgO} \cdot 1 \mathrm{Al}_{2} \mathrm{O}_{3}$ (a) and the $\mathrm{MgO} \cdot 3 \mathrm{Al}_{2} \mathrm{O}_{3}$ (b) spinel single crystals.

Fig. 5. The relationship of the classical Meyer's Law parameters $A$ and $n$ for the spinel single crystals.

Meyer's Law exponent, or the $n$-value, is different for the [001] and the [011] as the $n$-value for the former is less than that of the latter for both of these spinel single crystals. Table 2 summarizes the two Meyer's Law parameters, the $A$-values and the $n$ values, for these two spinel single crystals. Note that the [001] and [010] Meyer's Law parameters are identical in each crystal and that the results are symmetrical about the $[011]$ for each. It appears that there may exist some fundamental relationship between these two Meyer's Law parameters as the $A$ value appears to be inversely related to the $n$-value. This observation is confirmed in Fig. 5, which has an $r^{2}$ of 0.92 for the linear regression analysis. This figure illustrates that the same $n-A$ relationship exists for both the stoichiometric and the nonstoichiometric spinel single crystals, although the stoichiometric spinel exhibits larger $n$-values than the nonstoichiometric crystal. Secondly, for $A=0$, the $n$ value extrapolates to $2.03 \pm 0.04$, which confirms the applicability of Meyer's Law to these hardness results.

Considering the Meyer's Law behavior, the $n$ -

Table 2. Meyer's Law parameters of the $\mathrm{MgO} \cdot x \mathrm{Al}_{2} \mathrm{O}_{3}$ single crystals on the (100).

\begin{tabular}{|c|c|c|c|c|}
\hline (100)[uvw] & $A\left(g \cdot \mu m^{-n}\right)$ & $\mathbf{n}$ & $A\left(g \cdot \mu m^{-n}\right)$ & $\mathbf{n}$ \\
\hline & \multicolumn{2}{|c|}{$\mathrm{MgO} \cdot 1 \mathrm{Al}_{2} \mathrm{O}_{3}$} & \multicolumn{2}{|c|}{$\underline{\mathrm{MgO}^{2} \cdot \mathrm{Al}_{2} \mathrm{O}_{3}}$} \\
\hline$[001]$ & $0.23 \pm 0.01$ & $1.80 \pm 0.02$ & $0.37 \pm 0.01$ & $1.67 \pm 0.01$ \\
\hline $15^{\circ}$ & $0.19 \pm 0.02$ & $1.85 \pm 0.02$ & $0.30 \pm 0.01$ & $1.70 \pm 0.02$ \\
\hline $30^{\circ}$ & $0.18 \pm 0.01$ & $1.88 \pm 0.01$ & $0.23 \pm 0.02$ & $1.76 \pm 0.01$ \\
\hline [011] & $0.16 \pm 0.01$ & $1.85 \pm 0.01$ & $0.22 \pm 0.01$ & $1.77 \pm 0.02$ \\
\hline $60^{\circ}$ & $0.16 \pm 0.02$ & $1.88 \pm 0.02$ & $0.22 \pm 0.01$ & $1.78 \pm 0.02$ \\
\hline $75^{\circ}$ & $0.19 \pm 0.01$ & $1.84 \pm 0.01$ & $0.32 \pm 0.02$ & $1.68 \pm 0.01$ \\
\hline [010] & $0.23 \pm 0.02$ & $1.80 \pm 0.01$ & $0.36 \pm 0.01$ & $1.68 \pm 0.01$ \\
\hline
\end{tabular}

values of these two spinels are significantly different. Those for the stoichiometric spinel are consistently larger than those for the nonstoichiometric spinel, revealing that the indentation load/size effect is not the same for these two single crystal spinels. Since $n=2$ is indicative of an indentation load/size independent condition, it is logical that the greater the deviation of the $n$-value from two, the greater is the indentation load/size effect. Hence these results reveal that the stoichiometric $\mathrm{MgO} \cdot 1 \mathrm{Al}_{2} \mathrm{O}_{3}$ spinel single crystal experiences less of an indentation load/size effect during microindentation hardness testing than does the nonstoichiometric $\mathrm{MgO} \cdot 3 \mathrm{Al}_{2} \mathrm{O}_{3}$ spinel single crystal.

3.3 The indentation load/size effect, normalized Meyer's Law

The indentation load/size effect has been recently addressed for the microhardness of $\mathrm{LaB}_{6}$ single crystals through a normalized form of Meyer's Law by Li and Bradt. ${ }^{21)}$ They applied the criterion of indentation hardness/load independence, which is defined by a variation of hardness $(H)$ with respect to a change of indentation test load $(P)$ equal to zero, as:

$$
\partial H / \partial P=0
$$

to derive a nomalized form of Meyer's Law, which is:

$$
P=\frac{2 P_{\mathrm{c}}}{n}\left(\frac{d}{d_{\mathrm{o}}}\right)^{n}
$$

where $P_{\mathrm{c}}$ is the critical indentation test load beyond which the indentation load/size effect is diminished, and $d_{0}$ is a characteristic indentation size related to $P_{\mathrm{c}}$. According to other studies of the normalized form of Meyer's Law applied to different single crystals, including $\mathrm{LaB}_{6},{ }^{21)} \mathrm{TiO}_{2}{ }^{29)}$ and $\mathrm{SnO}_{2},{ }^{30}$ ) the Meyer's Law exponents or the $n$-values determined for experimental results analyzed by Eq. (5) are identical to those for the classical Meyer's Law of Eq. (2). The normalized form of Meyer's Law does, however, solve the dimensionality problem of the $A$ - 

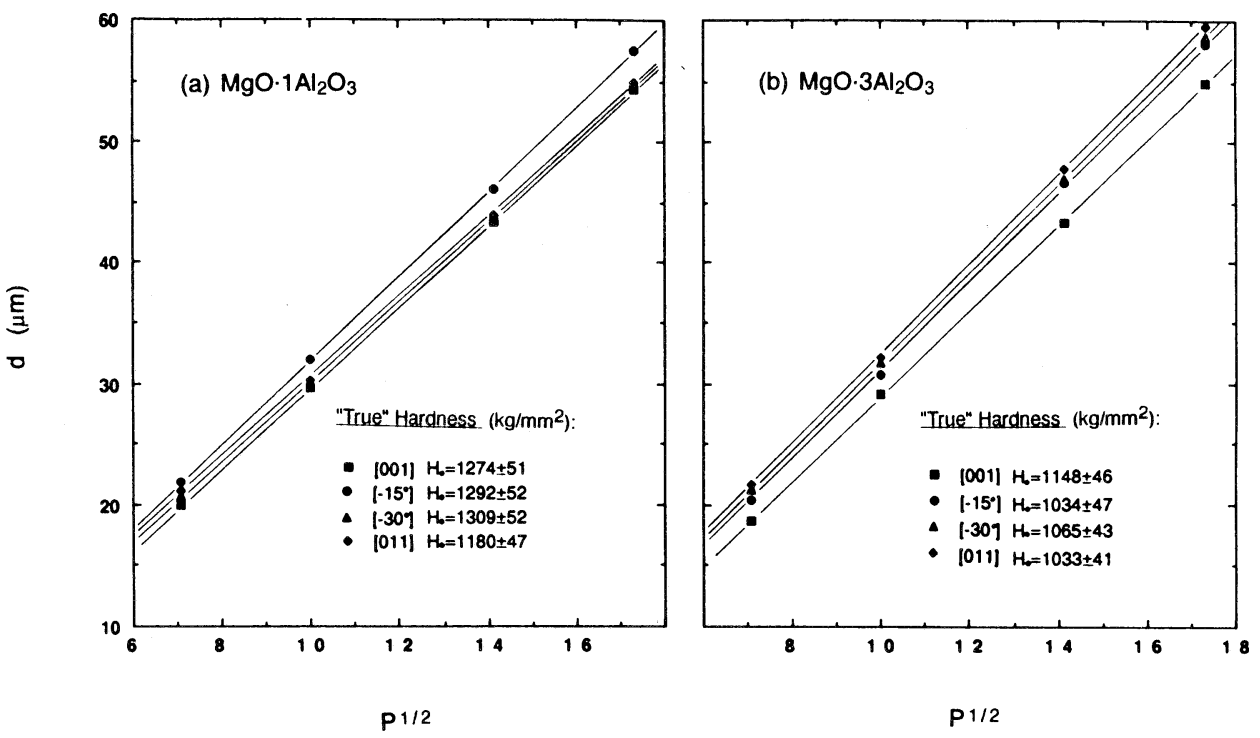

Fig. 6. The "true" hardness plots for the $\mathrm{MgO} \cdot 1 \mathrm{Al}_{2} \mathrm{O}_{3}$ (a) and the $\mathrm{MgO} \cdot 3 \mathrm{Al}_{2} \mathrm{O}_{3}$ (b) spinel single crystals.

value and also reveals the physical significance of the Meyer's Law through $P_{\mathrm{c}}$ and $d_{\mathrm{o}}$.

To apply Eq. (5) to the analysis of the indentation load/size effect, $P_{\mathrm{c}}$ and $d_{\mathrm{o}}$ must first be determined from the experimental microhardness results. For indentation load/size independence, the microhardness can be considered as a "true" hardness $\left(H_{0}\right)$. Under this condition, $d_{0}$ can be related to $H_{0}$ and calculated from:

$$
d_{0}=\left(\frac{2 H_{0}}{14229 n A}\right)^{1 /(n-2)}(\mu \mathrm{m})
$$

where the load-independent "true" hardness can be determined from experimental microhardness results, as described by $\mathrm{Larmie}^{31)}$ and $\mathrm{Li}$ et al., ${ }^{32)}$ in the form of:

$$
d=\left(14229 / H_{\mathrm{o}}\right)^{1 / 2} P^{1 / 2}+\delta \quad(\mu \mathrm{m})
$$

where $\delta$ is related to relaxation effects on unloading.

Figure 6 illustrates the $d$ versus $P^{1 / 2}$ plots for the evaluation of $H_{0}$ of the (100) planes for the two spinel single crystals. The "true" hardness $\left(H_{0}\right)$ values are obtained from the slopes of the linear regression lines. Table 3 summarizes the resulting "true" hardness values. For the stoichiometric spinel, they range from 1180 to $1274 \mathrm{~kg} / \mathrm{mm}^{2}$ and are consistently higher than the values of 1033 to $1145 \mathrm{~kg} / \mathrm{mm}^{2}$ for the nonstoichiometric spinel with respect to all directions on the (100) plane. This comparison clearly reveals that the stoichiometric spinel is harder than the nonstoichiometric spinel structure. Many studies ${ }^{4), 9), 12), 13)}$ of plastic deformation of $\mathrm{Mg}-\mathrm{Al}$ spinels at elevated temperatures confirm that the stoichiometric spinel is stronger than the nonstoichiometric spinels. At room temperature, the above conclusion is similar as revealed by the load-independent "true" hardnesses determined in this study.

The calculated "true" hardnesses can be applied to determine the characteristic indentation size $\left(d_{0}\right)$
Table 3. "True" hardnesses and characteristic indentation sizes of the $\mathrm{MgO} \cdot x \mathrm{Al}_{2} \mathrm{O}_{3}$ single crystals on the (100).

\begin{tabular}{ccccccc}
\hline (100)[uvw] & $\begin{array}{c}\mathrm{H}_{\mathrm{o}} \\
\left(\mathrm{kg} / \mathrm{mm}^{2}\right)\end{array}$ & $\begin{array}{c}\mathrm{d}_{\mathrm{o}} \\
(\mu \mathrm{m})\end{array}$ & $\begin{array}{c}\mathrm{P}_{\mathrm{c}} \\
(\mathrm{g})\end{array}$ & $\begin{array}{c}\mathrm{H}_{\mathrm{o}} \\
\left(\mathrm{kg} / \mathrm{mm}^{2}\right)\end{array}$ & $\begin{array}{c}\mathrm{d}_{\mathrm{o}} \\
(\mu \mathrm{m})\end{array}$ & $\begin{array}{c}\mathrm{P}_{\mathrm{c}} \\
(\mathrm{g})\end{array}$ \\
\hline \multirow{2}{*}[001]{} & $1274 \pm 51$ & $61.97 \pm 2.48$ & $344 \pm 21$ & $1148 \pm 46$ & $58.81 \pm 2.44$ & $279 \pm 20$ \\
\cline { 5 - 8 } & & & & & & \\
$15^{\circ}$ & $1292 \pm 52$ & $62.77 \pm 2.51$ & $358 \pm 20$ & $1034 \pm 47$ & $65.67 \pm 2.83$ & $313 \pm 22$ \\
$30^{\circ}$ & $1309 \pm 52$ & $67.75 \pm 2.03$ & $422 \pm 25$ & $1065 \pm 43$ & $68.26 \pm 2.73$ & $349 \pm 21$ \\
{$[011]$} & $1180 \pm 47$ & $63.63 \pm 2.55$ & $336 \pm 20$ & $1033 \pm 41$ & $65.73 \pm 2.63$ & $314 \pm 19$ \\
$60^{\circ}$ & $1324 \pm 53$ & $67.36 \pm 2.69$ & $422 \pm 30$ & $1067 \pm 42$ & $66.22 \pm 2.65$ & $329 \pm 23$ \\
$75^{\circ}$ & $1280 \pm 60$ & $65.62 \pm 2.63$ & $387 \pm 23$ & $1013 \pm 41$ & $63.59 \pm 2.54$ & $288 \pm 17$ \\
{$[010]$} & $1273 \pm 65$ & $60.58 \pm 3.03$ & $328 \pm 22$ & $1158 \pm 48$ & $58.71 \pm 2.35$ & $281 \pm 20$
\end{tabular}

through Eq. (6). Table 3 summarizes the characteristic indentation sizes, the $d_{0}$-values, for these two spinel single crystals. With respect to the average value of $d_{0}$ on the (001) plane, that for the stoichiometric spinel is essentially the same as that for the nonstoichiometric spinel: $64.24 \pm 2.56 \mu \mathrm{m}$ versus $63.81 \pm 2.55 \mu \mathrm{m}$. These calculated $d_{\mathrm{o}}$ values are comparable to the measured indentation sizes at the 300 $\mathrm{g}$ indentation test load for these spinel crystals, which is consistent with the observed indentation load/size effect on the (100) planes for these two spinel single crystals.

According to the calculated "true" hardness and the characteristic indentation sizes (the $d_{0}$-values), the critical indentation loads (the $P_{\mathrm{c}}$-values) can be determined and these are summarized in Table 3. The critical indentation loads are anisotropic with respect to indentation orientation on the (100). The stoichiometric $\mathrm{MgO} \cdot 1 \mathrm{Al}_{2} \mathrm{O}_{3}$ spinel has slightly higher $P_{\mathrm{c}}$-values than the nonstoichiometric $\mathrm{MgO} \cdot 3 \mathrm{Al}_{2} \mathrm{O}_{3}$ spinel. However, for both crystals, the

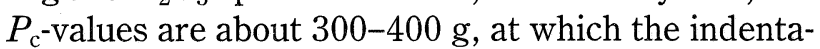



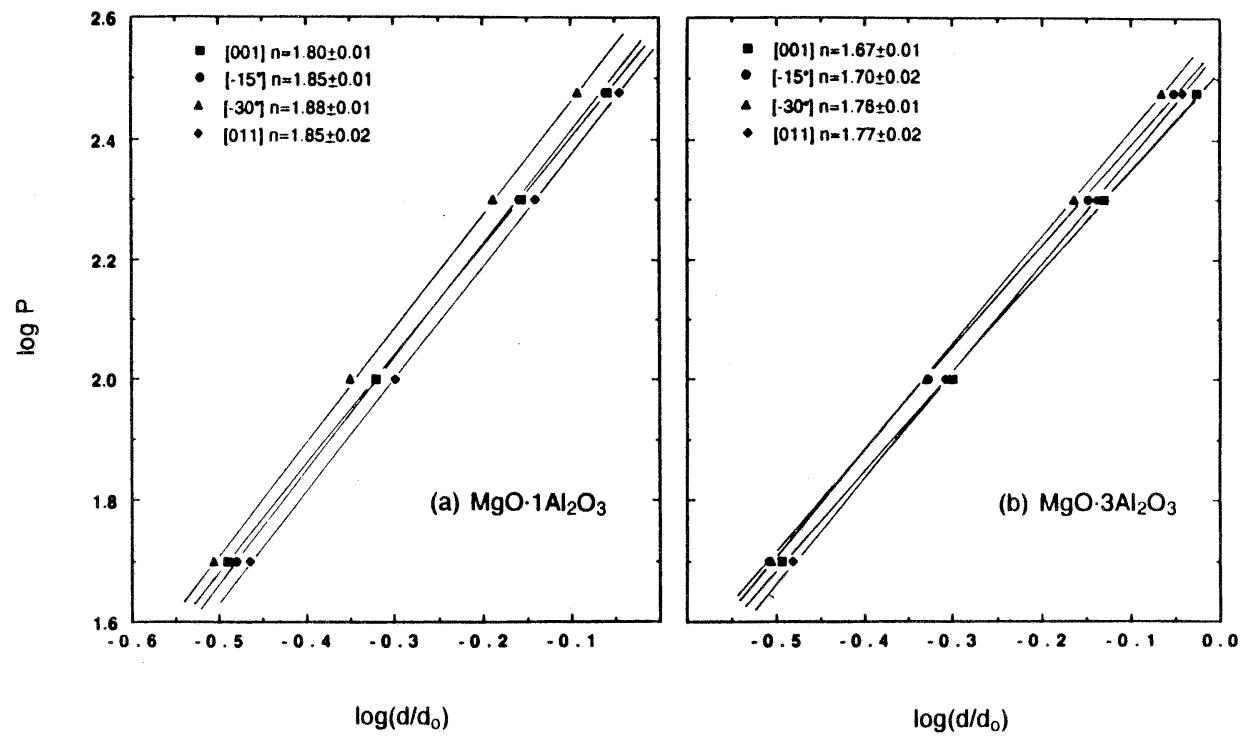

Fig. 7. The normalized Meyer's Law relationship on the (100) of the $\mathrm{MgO} \cdot 1 \mathrm{Al}_{2} \mathrm{O}_{3}$ (a) and the $\mathrm{MgO} \cdot 3 \mathrm{Al}_{2} \mathrm{O}_{3}$ (b) spinel single crystals.

tion load/size effect is significantly reduced, consistent with the experimental results.

Once these characteristic indentation sizes, the $d_{0}{ }^{-}$ values, have been calculated, the normalized Meyer's Law in the logarithmic form of Eq. (5), which is:

$$
\log P=\log \left(2 P_{\mathrm{c}} / n\right)+n \log \left(d / d_{\mathrm{o}}\right)
$$

can be applied to these crystals. Figures 7 (a) and 7 (b) illustrate these relationships of $\log P$ versus $\log \left(d / d_{0}\right)$ for the stoichiometric spinel and the nonstoichiometric spinels, respectively. The slopes of the regression lines yield the normalized Meyer's Law exponents which are identical to those of the classical Meyer's Law. It can be concluded that the normalized form of Meyer's Law is consistent with the experimental observations that the indentation load/size effect on the microhardness is significant when the indentation load is less than the critical indentation load $\left(P_{\mathrm{c}}\right)$, or the indentation size is less than the characteristic indentation size $\left(d_{0}\right)$. The normalized Meyer's Law provides a convenient way to asseses the extent of the indenation load/size effect on the microhardness in terms of the physical properties: a critical indentation test load $\left(P_{\mathrm{c}}\right)$ and a characteristic indentation size $\left(d_{0}\right)$.

Comparing the normalized form of Meyer's Law with the classical Meyer's Law, the physical meaning of the classical Meyer's Law coefficient $(A)$ can be better understood. It is revealed to be related to the critical indentation test load $\left(P_{\mathrm{c}}\right)$ and the characteristic indentation size $\left(d_{0}\right)$, as well as the Meyer's Law exponent, the $n$-value. This is evident when Eqs. (2) and (5) are combined, yielding the Meyer's Law coefficient $(A)$ expressed as:

$$
A=\frac{2 P_{\mathrm{c}}}{n d_{\mathrm{o}}^{n}}
$$

This illustrates that the $A$-value is indeed inversely related to the $n$-value as previously discussed and confirmed by the results presented in Fig. 5 . Sargent and Page ${ }^{33)}$ have also studied correlations between the $A$-values and the $n$-values, but for polycrystalline ceramics rather than single crystals. They observed that there exists a degree of correlation where the $n$ value appears to be inversely related to the $\ln (A)$. However, for polycrystalline ceramics, the grain boundary effect also directly affects the indentation measurement results. As a consequence, the $A-n$ relationship is not as obvious for polycrystalline specimens, as it is revealed for the single crystals in this study and illustrated in Fig. 5.

As clearly presented by the above discussion, some features of the indentation load/size effect on the microhardness can be quantitatively described by applying the normalized form of Meyer's Law. However, the physical significance of the Meyer's Law exponent, or the $n$-value remains unresolved even in the normalized form. Although the $n$-value has been defined and confirmed as a parameter directly associated with the indentation load/size effect, ${ }^{34)}$ there exists no consistent agreement among many researchers as to its fundamental origin. Some explanations include the material resistance pressure effect, ${ }^{23)}$ dislocation source hardening, ${ }^{26)}$ interaction between the dislocations and the surface, ${ }^{35)}$ work hardening ${ }^{25)}$ and the elastic recovery effect. ${ }^{36)-40)}$ It has been substantiated, however, that harder materials often experience the more significant indentation load/size effect in the microindentation hardness test, although these two spinels do not follow that trend. Further investigation of the Meyer's Law exponent, the $n$-value, is required to gain additional insight of the response of the material to the indentation load.

\section{Summary and conclusions}

The Knoop microhardness profiles were deter- 
mined on the (100) planes of stoichiometric $\left(\mathrm{MgO} \cdot 1 \mathrm{Al}_{2} \mathrm{O}_{3}\right)$ spinel and nonstoichiometric $\left(\mathrm{MgO} \cdot 3 \mathrm{Al}_{2} \mathrm{O}_{3}\right)$ spinel single crystals for indentation test loads from 50 to $300 \mathrm{~g}$. The microhardness results indicate that the hardnesses of the two $\mathrm{Mg}$ Al spinel single crystals are highly anisotropic on the (100) planes. The extent of the hardness anisotropy for the stoichiometric spinel is consistently less than that for the nonstoichiometric spinel. Analysis of the indentation load/size effect on the extent of the microhardness anisotropy illustrates that the latter decreases with an increase of the indentation test load. The trend appears to follow a power law, but this phenomenon requires further investigation.

The Knoop microhardness profiles were compared with the calculated ERSS diagrams. The latter were calculated with the assumption that the $\{111\}\langle 1 \overline{1} 0\rangle$ slip system is dominant for the stoichiometric spinel and yielded good agreement with the experimental microhardness profile. As the consequence of these analyses, it is suggested that at room temperature the Knoop microhardness anisotropy of the stoichiometric and the nonstoichiometric spinel crystals are both controlled by the $\{111\}\langle 1 \overline{1} 0\rangle$ primary slip system. The $\{110\}\langle 1 \overline{1} 0\rangle$ slip system appears to make only a minor contribution, even for the nonstoichiometric spinel and perhaps only near the $\langle 100\rangle$ orientations.

The indentation load/size effect was addressed through both the classical Meyer's Law and the normalized form of the Meyer's Law. The normalized Meyer's Law was confirmed to be consistent with the classical Meyer's Law through the experimental data, as the power law exponents or $n$-values are the same. According to the Meyer's Law analysis, the Meyer's Law coefficient $(A)$ is inversely related to the Meyer's Law exponent $(n)$ for both of these spinel single crystals. The $n$-values for the stoichiometric spinel are consistently higher than those of the nonstoichiometric spinel. The calculated critical indentation test load $\left(P_{\mathrm{c}}\right)$ and the characteristic indentation size $\left(d_{0}\right)$ were consistent with the experimental results. The results suggest that the Meyer's Law parameters are anisotropic in nature, revealing that the indentation load/size effect varies with both the spinel stoichiometry and the crystallographic orientation.

\section{References}

1) J. Hornstra, J. Phys. Chem. Solids, 15, 311-23 (1960).

2) D. M. Choi and H. Palmour III, "Materials Science Research", Vol. 3, Ed. by W. W. Kriegel and H. Palmour III, Plenum Press, New York (1966) pp. 473-82.

3) M. H. Lewis, Phil. Mag., 17, 481-99 (1968).

4) C. W. A. Newey and K. C. Radford, "Anisotropy in SingleCrystal Refractory Compounds", Vol. 2, Ed. by F. W. Vahldiek and S. A. Mersol, Plenum Press, New York (1968) pp. 321-38.

5) N. Doukhan, R. Duclos and B. Escaig, J. de Phys. Colloq., C9, 379-87 (1973).

6) N. Doukhan, R. Duclos and B. Escaig, J. de Phys. Colloq.,
C7, 556-71 (1976).

7) L. Hwang, A. H. Heuer and T. E. Mitchell, "Deformation of Ceramic Materials”, Ed. by R. C. Bradt and R. E. Tressler, Plenum Press, New York (1975) pp. 254-70.

8) T. E. Mitchell, L. Hwang and A. H. Heuer, J. Mater. Sci., 11, 264-72 (1976).

9) W. T. Donlon, T. E. Mitchell and A. H. Heuer, Phil. Mag., A 40, 351-66 (1979).

10) H. Suematsu, T. Suzuki and T. Iseki, J. Am. Ceram. Soc., 72, 306-08 (1989).

11) H. Suematsu, T. Suzuki and T. Iseki, J. Am. Ceram. Soc., 72, 1449-52 (1989).

12) G. Welsch, L. Hwang, A. H. Heuer and T. E. Mitchell, Phil. Mag., 29, 1371-79 (1974).

13) R. Duclos, N. Doukhan and B. Escaig, Acta Metall., 30, 1381-88 (1982).

14) L. G. Berry and B. Mason, "Mineralogy", W. H. Freeman and Company, San Francisco (1959) pp. 596.

15) B. B. Young and A. P. Millman, Trans. I.M.M., 73, 437-66 (1964).

16) Y. Akimune and R. C. Bradt, J. Am. Ceram. Soc., 70, C8486 (1987).

17) D. Viechnicki, F. Schmid and J. W. McCauley, J. Appl. Phys., 43, 4508-12 (1972).

18) G. K. Bansal and A. H. Heuer, Phil. Mag., 29, 709-22 (1974).

19) S. J. Zinkle, J. Am. Ceram. Soc., 72, 1343-51 (1989).

20) E. Meyer, Zeitschrift, V.D.I., 52, 645 (1908).

21) H. Li and R. C. Bradt, to be published in Mater. Sci. Eng..

22) T. Ito, J. Am. Ceram. Soc., 54, 24-26 (1971).

23) E. H. L. J. Dekker and G. D. Rieck, J. Mater. Sci., 9, 183946 (1974).

24) C. A. Brookes, J. B. O'Neill and B. A. W. Redfern, Proc. Roy. Soc. London, A322, 73-88 (1971).

25) B. W. Mott, "Micro-indentation Hardness Testing", Butterworths Scientific Publication, London (1956) pp. 101-39.

26) N. Gane and J. M. Cox, Phil. Mag., 22, 881-91 (1970).

27) D. J. Clinton and R. Morrell, Mater. Chem. Phys., 17, 46173 (1987).

28) C. Hays and E. G. Kendall, Metallog., 6, 275-82 (1973).

29) H. Li and R. C. Bradt, J. Am. Ceram. Soc., 73, 1360-64 (1990).

30) H. Li and R. C. Bradt, J. Am. Ceram. Soc., 74, 1053-60 (1991).

31) H. A. Larmie, Ph.D. dissertation, Univ. of Washington, Seattle, WA, 1988.

32) Z. Li, A. Ghosh, A. S. Kobayashi and R. C. Bradt, J. Am. Ceram. Soc., 72, 904-11 (1989).

33) P. M. Sargent and T. F. Page, Proc. Brit. Ceram Soc., 26, 209-24 (1978).

34) P. M. Sargent, "Microindentation Techniques in Materials Science and Engineering", Ed. by P. J. Blau and B. R. Lawn, ASTM STP 889, Philadelphia, PA (1984) pp. 160-74.

35) G. P. Upit and S. A. Varchenya, "The Science of Hardness Testing and Its Research Applications", Ed. by J. H. Westbrook and H. Conrad, ASM, Metal Park, Ohio (1973) pp. $135-46$.

36) P. M. Sargent and T. F. Page, Scripta Metal., 15, 245-50 (1980).

37) J. L. Loubet, J. M. Georges, O. Marchesini and G. Meille, J. Tribology, 106, 43-48 (1984).

38) J. L. Loubet, J. M. Georges and G. Meille, "Microindentation Techniques in Materials Science and Engineering," Ed. by P. J. Blau and B. R. Lawn, ASTM STP 889, Phil., PA (1984) pp. 72-89.

39) M. F. Doerner and W. D. Nix, J. Mater. Res., 1, 601-09 (1986).

40) G. M. Pharr and R. E. Cook, J. Mater. Res., 5, 847-51 (1990). 